Revista Eletrônica do Mestrado em Educação Ambienta1

Programa de Pós-Graduação em Educação Ambiental

\title{
Pensamiento Crítico: Actitud Vital para Convivir ${ }^{1}$
}

\author{
Linda Marcela Gallego Jaramillo \\ Universidad de Manizales \\ http://orcid.org/0000-0002-6412-6644 \\ Martha Lucia García Naranjo ${ }^{3}$ \\ Universidad de Manizales \\ http://orcid.org/0000-0002-7232-953X
}

Resumen: Se presenta la reflexión teórica sobre las prácticas pedagógicas para el pensamiento crítico en programas de pregrado y posgrado. El objetivo fue comprender las prácticas pedagógicas para el pensamiento desde la racionalidad y razonabilidad. La metodología comprensiva envarios momentos exploración, contrastación y comprensión. Se centró en el papel del docente como sujeto que reflexiona y comprende su práctica. La contribución es la reflexión sobre la práctica pedagógica y la formación en pensamiento crítico y los aspectos que contribuyen. El resultado permitió comprender que las prácticas pedagógicas para la formación en pensamiento crítico apuntan a formar en los estudiantes la capacidad de razonamiento disciplinar, conocimiento del contexto, habilidades investigativas y motivaciones que configuren una actitud vital en este tipo de pensamiento. Por otra parte, a la razonabilidad aportan a que los sujetos aprendan a vivir juntos, sean sensibles al contexto y desarrollen sentido social.

Palabras claves: Práctica Pedagógica, Racionalidad, Razonabilidad, Pensamiento Crítico

\section{Pensamento Crítico: Atitude Vital Para Conviver}

Resumo: É apresentada a reflexão teórica sobre práticas pedagógicas para o pensamento crítico nos cursos de graduação e pós-graduação. $\mathrm{O}$ objetivo era compreender as práticas pedagógicas do pensamento a partir da racionalidade e da razoabilidade. Metodologia abrangente em vários momentos de exploração, contraste e compreensão. Ele se concentrou no papel do professor como

\footnotetext{
${ }^{1}$ El artículo de reflexión teórica se deriva del proyecto de investigación "Las prácticas pedagógicas para el desarrollo del pensamiento crítico en los programas de pregrado y postgrado de la Universidad de Manizales"Caldas. Colombia

${ }^{2}$ Magister en Educación y Desarrollo Humano. Licenciada en Educación Especial, Universidad de Manizales. E-mail: mgallego@umanizales.edu.co.

${ }^{3}$ Doctorado en Educación (C). Magister en Educación. Docencia. Ingeniera de Sistemas. Docente Centro de investigaciones en Medio Ambiente y Desarrollo Universidad de Manizales. e-mail: marthalgn@umanizales.edu.co.
}

Rev. Eletrônica Mestr. Educ. Ambient. Rio Grande, v. 36, n. 3, p.141-159, set./dez. 2019.

E-ISSN 1517-1256 
um sujeito que reflete e entende sua prática. A contribuição é a reflexão sobre a prática pedagógica e a formação em pensamento crítico e os aspectos que contribuem. $\mathrm{O}$ resultado nos permitiu entender que as práticas pedagógicas para treinamento em pensamento crítico visam treinar os alunos na capacidade de raciocínio disciplinar, conhecimento de contexto, habilidades de pesquisa e motivações que moldam uma atitude vital nesse tipo de pensamento. Por outro lado, contribuem para a razoabilidade, para que os sujeitos aprendam a conviver, sejam sensíveis ao contexto e desenvolvam um senso social.

Palavras chave: Prática Pedagógica, Racionalidade, Razoabilidade, Pensamento Crítico

\title{
Critical Thinking: Vital Attitude to Live Together
}

\begin{abstract}
The theoretical reflection on pedagogical practices for critical thinking in undergraduate and postgraduate programs is presented. The objective was to understand pedagogical practices for thinking from rationality and reasonableness. Comprehensive methodology at various times exploration, contrast and understanding. He focused on the role of the teacher as a subject who reflects and understands his practice. The contribution is the reflection on pedagogical practice and training in critical thinking and the aspects that contribute. The result allowed us to understand that pedagogical practices for training in critical thinking aim to train students in the ability to discipline reasoning, context knowledge, research skills and motivations that shape a vital attitude in this type of thinking. On the other hand, they contribute to reasonableness so that the subjects learn to live together, are sensitive to the context and develop a social sense.
\end{abstract}

Key words: Pedagogical Practice, Rationality, Reasonableness, Critical Thinking

\section{INTRODUCCIÓN}

Se realiza la reflexión teórica sobre la práctica pedagógica, la que vista de manera holística se entiende como un conjunto de acciones educativas institucionalizadas e intencionadas en las que el docente convierte en discurso y acción sus saberes disciplinares, los cuales son adaptados a los contextos y situaciones sociales específicas. Dado que estas acciones son ejecutadas por los docentes, en ellas entran en juego los saberes pedagógicos disciplinares, las experiencias y las reflexiones sobre dichos saberes y acciones; por eso la práctica pedagógica se mueve en una relación de interdependencia entre saber, acción, reflexión, experiencia.

La reflexión teórica se presenta en tresapartados, el primero aborda el concepto de práctica pedagógica como un conjunto de acciones educativas institucionalizadas, intencionadas en las que el docente convierte en discurso y acción sus saberes disciplinares, los cuales son adaptados a los contextos y situaciones sociales específicas. Para ello se parte delos aportes de Zuluaga (1999), Zambrano (1963),Barrera(2009), CarrKemmis(1986) y Martín (2009); y se contrasta con algunas investigaciones sobre el tema.

Rev. Eletrônica Mestr. Educ. Ambient. Rio Grande, v. 36, n. 3, p. 141-159, set./dez. 2019. E-ISSN 1517-1256 
El segundo es metodológico, en el relacionan el enfoque y los diferentes momentos metodológicos; el primero fue de exploración, Seguidamente la contrastación que implicó el debatir entre la teoría y los lineamientos institucionales. Y finalmente la comprensión de la relación entre las prácticas pedagógicas la racionalidad y razonabilidad.

El tercer apartado intenta categorizar las habilidades de pensamientos que se potencian a partir de las prácticas pedagógicas intencionadas para la formación en la racionalidad y la razonabilidad. En la racionalidad se reconoce la formación disciplinar, las habilidades investigativas, el conocimiento del contexto y el pensamiento crítico como actitud vital. Y en la razonabilidad el sentido social, el vivir juntos y la sensibilidad al contexto. Se parte de las concepciones y características del pensamiento crítico que presentan los autores Ennis(1987), Paul(1989), Tardif(1992), Beyer(1987), Neuwmann(1990) y Glatthom\&Baron (1985).

\section{FUNDAMENTACIÓN LAS PRÁCTICAS PEDAGÓGICAS ARTICULACIÓN ENTRE LA REFLEXIÓN Y LA ACCIÓN}

La práctica pedagógica se entiende como las acciones educativas en el contexto institucional, al respecto Zuluzaga (1999) plantea que: "la práctica pedagógica debe entenderse como un modo de ser, como una forma de funcionamiento de la institución que permite la apropiación de saberes, inserción en la producción e investigación, experimentación para apropiar conocimientos y reconceptualizar" (p. 1). Para la autora, el profesor desarrolla un método en el cual transforma el discurso del conocimiento en contenidos para la enseñanza, en ese sentido la pedagogía no es sólo un discurso acerca de la enseñanza, sino también una práctica cuyo campo de aplicación es el discurso. Por tal razón se reconoce la importancia del profesor en esta relación discursiva.En sus palabras el profesor enfrenta los conocimientos pedagógicos al discurso de las "teorías" o de las "ciencias" y el instrumento que utiliza para ello es el método de enseñanza.En este orden de ideas eldocente ajusta los discursos y métodos a las necesidades y particularidades de los estudiantes de acuerdo con criterios como la edad y el contexto, entre otros.En síntesis, la práctica pedagógica se da a nivel institucional y son discursos teóricos disciplinares adaptados a las necesidades del contexto, lo que para el presente artículo significaría formación en pensamiento crítico disciplinar.

Rev. Eletrônica Mestr. Educ. Ambient. Rio Grande, v. 36, n. 3, p. 141-159, set./dez. 2019. 
La autora considera que la práctica pedagógica se vincula con la pedagogía, y responde a procesos específicos de cada saber y la pedagogía para ella es una disciplina específica que se encarga de los métodos de enseñanza que tienen un contexto social. Entonces se reconoce a la pedagogía como la adecuación social de los saberes en las diferentes culturas.

Vista la pedagogía de ese modo el espacio que convoca la relación entre Pedagogía y la práctica pedagógica es un espacio del saber en el cual unas regiones de conceptos de las disciplinas o teorías tienen una forma de existencia social en las instituciones. (Zuluaga,1999,p.44)

Algunas investigaciones consideran que la práctica en la universidad se ha de orientar al fomento en los estudiantes con la conciencia de aprender, la capacidad de estudiar y del rigor intelectual.(Parra y Vergara, 2003). Mediante un proceso consciente, deliberado, participativo con el objeto de mejorar desempeños y resultados, estimular el desarrollo de la renovación de campos académicos, profesionales o laborales y formar el espíritu de compromiso de cada persona con la sociedad y particularmente para la comunidad en la cual se desenvuelve (Huberman, 1999).

Involucrar el pensamiento crítico disciplinar en la formación implica partir de un concepto claro y justificable que facilite diagnosticar los niveles de crítica de los estudiantes, promover retroalimentación y fortalecer sus habilidades de pensamiento, por medio de experiencias significativas de aprendizaje fundamentadas en las realidades de los estudiantes, experiencias, vivencias que den relevancia al sentido y significado que estos asignan a la disciplina en que se forman, en otras palabras el pensamiento racional y reflexivo al servicio de la acción.Zambrano(2005) considera que el ejercicio de la educación basado en unas prácticas pedagógicas busca otorgar a los sujetos autonomía mediante la puesta en escena de las prácticas de enseñanza- aprendizaje, que los conduzca a un mejor desempeño como miembros de una sociedad.

Así lo manifiesta el autor "Toda acción educativa busca formar en los sujetos una conciencia de ciudadanos. Ser ciudadano implica reconocer que se está en un lugar y este es importante para existir" (p.80); el ser ciudadano es ser razonable, es decir, pensar u obrar acorde a un juicio sano, justo, equitativo, en todas las áreas del accionar humano. De tal manera que la razonabilidad favorece la búsqueda de una convivencia equitativa en sociedades plurales. Por esto Zambrano señala la importancia de que el profesor tenga presente que en el aprendizaje hay tiempo, memoria, espacios, historia, objetos, intelecto, 
deseo, placer, angustia, además de otras variables que impiden la reducción del mismo a la simple combinación entre objetos del saber y facultades intelectuales.

Para el autor la formación es aprendizaje desde la perspectiva de la experiencia; al respecto, Díaz (1990) da importancia a los procedimientos, estrategias y prácticas que regulan la interacción, la comunicación, el ejercicio del pensamiento, del habla, de la visión, de las posiciones, oposiciones y disposiciones de los sujetos en la escuela. Estas experiencias reconocen al aprendizaje como su vector más importante, en el que se ve cada situación que enfrenta el sujeto como una oportunidad de transformación.

También, la práctica pedagógica es una actividad estratégica asociada con la cultura en la que sereconoce la experiencia del profesor y dicha experiencia se constituye en un saber pedagógico (Barrera, 2009),para el autor la práctica pedagógica es el fundamento de la reflexión y del pensamiento, dado que hace parte de la experiencia vivida cómo una acción reflexiva que estructura al saber pedagógico. En el que tienen un papel importante las interacciones entre los docentes con los estudiantes, sus pares y el mismo entorno; y se enriquece con las problemáticas y el trabajo en colaboración.

Sin embargo,en este saber pedagógico el profesor integra otros saberes como: el saber profesional, disciplinar, curricular, experiencial y pedagógico. Ahora bien, lo que diferencia al saber pedagógico de los otros saberes, es que su origen está en la acción reflexiva que desarrolla el docente respecto de su práctica.Para Barrera, la reflexión de la práctica pedagógica incluye también aspectos metodológicos,es decir, la manera, el contexto y la dinámica comose realiza la enseñanza-aprendizajeEn consecuencia, segúnFayad(2002)el sujeto que reflexiona acerca de su práctica docente ubica como referencia un saber que remite al hacer artesanal, al pensar más que aun hacer. Desde esta perspectiva para autores como Martínez(1990), la práctica pedagógica se asume como una categoría metodológica, un objeto conceptual y también como una noción estratégica en tanto práctica de saber que articula tres elementos metodológicos fundamentales: una institución, la escuela; un sujeto soporte de esa práctica, el maestro; y un saber, el saber pedagógico. Y para Ortega(2005)una noción metodológica articula realidades tanto prácticas como conceptuales que circulan en las instituciones educativas, así las prácticas pedagógicas entran en relación interdependiente con el saber pedagógico. Este presupone las prácticas pedagógicas y viceversa. Es así como la práctica del saber refiere a la distribución, adecuación y control de los saberes en la escuela.

Una manera de identificar la complementariedad entre la apuesta de Zuluaga y la de Barrera se ve en los planteamientos deCarr yKemmis(1986) respecto a la teoría educativa Rev. Eletrônica Mestr. Educ. Ambient. Rio Grande, v. 36, n. 3, p. 141-159, set./dez. 2019. E-ISSN 1517-1256 
en la que los autores consideran que se constituye en una práctica dado que su verdadera finalidad es permitir que los profesores reflexionen en torno a su propia práctica y la manera de reducir la distancia entre la teoría y la práctica es mantener la reflexión pedagógica, ya que estase encarga de hacerle una crítica a las disciplinas creando nuevos teoremas e identificándolos en el contexto para llevarlos a cabo y definir los métodos de aplicación. En ese sentido desde la perspectiva de Carr yKemmis(1986) se comparte la necesidad de la reflexión o la autocrítica que realizan los profesores en sus prácticas pedagógicas. Al respecto, Freire(2004) propone la reflexión acerca de la práctica como vehículo de articulación entre la teoría y la práctica educativa crítica, con el fin de mejorar las prácticas venideras, incorporando la reflexión, análisis y la reconstrucción. Afirma que la práctica está implícita en el pensar acertadamente, el movimiento dinámico-dialéctico entre el hacer y el pensar sobre el hacer. Además, promueve unas tareas específicas dentro de las cuales rescata el desarrollo de la curiosidad y el asumirse como ser social e histórico

La práctica pedagógica desde las perspectivas mencionadas se encarga de posibilitar escenarios de reflexión y pensamiento crítico sobre las teorías que fundamentan lo disciplinar.Se entiende, estos escenarios como entornos escolares tradicionales y mediados por las TIC; donde se potencia el desarrollo humanoen todas sus dimensiones: disciplinar, axiológica, ética, política, humana que favorecen una construcción y reflexión diaria permanenteen la que se abrenabanicos de alternativas para la formación del estudiante, que asegure la diversidad y la vida en relación social. Desde esta perspectiva la práctica pedagógica integra lo humano, social y cultural en procesos de enseñanzaaprendizaje en el ámbito escolar, familiar y social.

Considerar la práctica pedagógica en la amplitud que exige la formación antes mencionada requiere la racionalidad de la práctica pedagógica por parte del maestro.Martín(2009), intenta hacer un acercamiento de lo que es la racionalidad pedagógica desde la intencionalidad que le es constitutiva a esta práctica. Todo proceso pedagógico implica un por qué, un motivo por el cual se realizará, partir de un objetivo para llegar a un punto, una razón. En ese sentido existe una racionalidad pedagógica, que permite tomar las diferentes herramientas del proceso educativo, para lograr una serie de acciones que lleven al cumplimiento de una intencionalidad. Es decir, se presenta una acción pedagógica, que no se encuentra dentro del campo de lo teórico, sino que justamente traspasa esa teoría y entra a generar una transformación en el mundo. Sin embargo, esa acción pedagógica requiere de planeación, de un ejercicio intelectual, de una razón que establezca un orden.En ese sentido, es posible definir la racionalidad pedagógica kev. wetronica lviestr. rauc. Amoient. K10 Granae, v. s0, n. 5, p. 141-1כy, set./aez. ¿uiy. E-ISSN 1517-1256 
como un proceso intelectual y al mismo tiempo como un proceso de organización que se da en el docente con el fin de desarrollar una práctica pedagógica.

Por suparte,Bellocchio(2005) aborda la racionalidad pedagógica de una manera más amplia, para la autora hay diferentes tipos de racionalidad, pero es justamente la racionalidad pedagógica la que encierra a todas ellas. Bellocchio expone que

la racionalidad lógica implica coherencia, manejo de la univocidad, incluso, el no caer en contradicciones durante el discurso; una racionalidad comunicativa, que permita adquirir habilidades de entendimiento, pero al mismo tiempo de crítica; una racionalidad gnoseológica, con la que el individuo construye una imagen del mundo, podría decirse su visión personal sobre el mundo, lo que incluiría la visión que se tiene sobre temas generales como el arte, la existencia, la política, la ciencia, etc.La racionalidad teleológica, que apuntaría al estudio de los fines, el para qué se va a realizar cada acción; una racionalidad mesológica, que ya versa sobre los medios que el individuo va a utilizar para conseguir los fines que se ha propuesto (Bellocchio Albornoz, 2005, págs. 144-145)

Por lo anterior, el quehacer docente orientado desde la racionalidad pedagógica, se convierte en un ejercicio de reflexión permanente que busca educar al estudiante más allá de lo requerido en el aula, involucrándolo de manera activa con su contexto a través de experiencias significativas de aprendizaje que le permitan desarrollar habilidades necesarias que le facilite enfrentarse eficazmente a las exigencias y retos de la vida diaria en relación con lo disciplinar.Desde esta perspectiva paraSaúl(2002)la práctica pedagógica es una propuesta de la pedagogía como proceso mediador del conocimiento, en el cual el educador debe tener claridad del trabajo pedagógico para contribuir en un proceso autónomo. La práctica pedagógica vista desde la racionalidad y la razonabilidadse enfoca a la formación del pensamiento crítico disciplinar y social y a su vez, a potenciar aquellas habilidades que no son contempladas en los currículos disciplinares, como aprender a vivir juntos, sensibilidad a las problemáticas de contexto, sentido socialempatía,autoconocimiento, toma de decisiones, inteligencia emocional, comunicación asertiva y resolución de conflictos entre otras.

\section{METODOLOGÍA}

El recorrido metodológico tuvolas siguientes:

Rev. Eletrônica Mestr. Educ. Ambient. Rio Grande, v. 36, n. 3, p. 141-159, set./dez. 2019. 
Momento de exploración conceptual: inició con la revisión teórica y de antecedentes investigativos para la construcción del concepto "práctica pedagógica", la identificación de sus fines, intencionalidades y características; así mismo los roles de los docentes y estudiantes. Este primer acercamiento teórico dio pie para los cuestionamientos en torno al enfoque de la práctica pedagógica para la formación en pensamiento crítico.

Momento de contrastación: Partiendo de lo anterior y con apoyo de la lectura crítica de documentos teóricos, investigativos y otras fuentes secundarias se logró debatir, definir y comprender las relaciones entre la práctica pedagógica para el pensamiento crítico racional y razonable. Se tomó como fuente Sistema de Planificación Institucional y los documentos maestros de los programas; los cuales sirvieron como insumo para construir una mirada alrededor de los lineamientos, pensamiento y prácticas pedagógicas sobre el pensamiento crítico.

Momento comprensivo: A partir del análisis documental y los debates teóricos de las fuentes consultadas se llegó a un momento comprensivo que entregó elementos valiosos sobre la interdependencia entre la formación disciplinar profesional y la formación social a través de las prácticas pedagógicas vistas desde los lineamientos planteados por la Universidad y las apuestas teóricas de base, con esto se intenta dar cuenta de una posible categorización de las habilidades para el pensamiento crítico racional y razonable.

\section{RESULTADOS Y DISCUSIÓN}

\section{Práctica Pedagógica Para Pensamiento Crítico Racional Y Razonable}

En la universidad las prácticas pedagógicas se comprenden comouna praxis, un discurso, una mediación y/o una perspectivacrítica para la formación, entre otras. Se articulan con el currículo en modos de organización tradicionales como núcleos y áreas de formación; y organización alternativa como campos didácticos de actuación y escenarios dialógicos. Estas se despliegan en escenarios como el aula yel contexto donde se realizan prácticas educativas y semilleros de investigación.Las prácticas pedagógicas reconocen los principios de la racionalidad y la razonabilidad. Así el pensamiento crítico en lo racional disciplinar tiene que ver con el desarrollo de habilidades disciplinares, investigativas, conocimiento del contexto y actitud vital; como se presenta en el cuadro Dimensiones del pensamiento crítico desde la racionalidad. Y en el cual se realiza la clasificación aplicable kev. wetronica lviestr. rauc. Amoient. K10 Granae, v. s0, n. 5, p. 141-1כy, set./aez. ¿uiy. E-ISSN 1517-1256 
al quehacer del docente, de acuerdo con autores comoEnnis(1987), Paul(1989), Tardif(1992), Beyer(1987), Neuwmann(1990) y Glatthom\&Baron (1985).

Cuadro 1. Habilidades de pensamiento crítico racional

\begin{tabular}{|c|c|c|c|c|}
\hline Autor & $\begin{array}{l}\text { Habilidades } \\
\text { investigativas }\end{array}$ & $\begin{array}{l}\text { Formación desde } \\
\text { lo disciplinar }\end{array}$ & $\begin{array}{l}\text { Conocimiento } \\
\text { del contexto }\end{array}$ & Actitud vital \\
\hline $\begin{array}{l}\text { Ennis } \\
1987\end{array}$ & $\begin{array}{l}\text { Evaluar de la } \\
\text { credibilidad de } \\
\text { una fuente. } \\
\text { Observar y } \\
\text { valorar de } \\
\text { informes de } \\
\text { observación. } \\
\text { Formular y } \\
\text { Valorar de juicios } \\
\text { de valor. } \\
\text { Buscar } \\
\text { precisiones en la } \\
\text { medida que el } \\
\text { tema lo permita. }\end{array}$ & & $\begin{array}{l}\text { Analizar de los } \\
\text { argumentos. } \\
\text { Interactuar con } \\
\text { los demás (por } \\
\text { ejemplo, } \\
\text { presentar } \\
\text { argumentos a } \\
\text { otras personas en } \\
\text { forma oral o } \\
\text { escrita). } \\
\text { Procurar una } \\
\text { enunciación } \\
\text { clara del } \\
\text { problema o de la } \\
\text { postura. } \\
\text { Considerar la } \\
\text { situación en su } \\
\text { conjunto. } \\
\text { Examinar las } \\
\text { diversas } \\
\text { perspectivas } \\
\text { disponibles. } \\
\text { Mostrar una } \\
\text { tendencia a } \\
\text { adoptar una } \\
\text { postura (y a } \\
\text { modificarla) } \\
\text { cuando los } \\
\text { hechos lo } \\
\text { justifiquen o } \\
\text { existan razones } \\
\text { suficientes para } \\
\text { hacerlo. } \\
\text { Considerar los } \\
\text { sentimientos de } \\
\text { los demás, así } \\
\text { como de su }\end{array}$ & $\begin{array}{l}\text { Concentrar su } \\
\text { atención en un } \\
\text { asunto. } \\
\text { Tender a buscar } \\
\text { las razones de } \\
\text { los fenómenos. } \\
\text { Mostrar un } \\
\text { esfuerzo } \\
\text { constante por } \\
\text { estar informado. } \\
\text { Mantener la } \\
\text { atención el tema } \\
\text { principal. } \\
\text { Procurar } \\
\text { conservar el } \\
\text { ánimo inicial. } \\
\text { Manifestar una } \\
\text { mente abierta. } \\
\text { Procurar la } \\
\text { aplicación de las } \\
\text { capacidades del } \\
\text { pensamiento } \\
\text { crítico. }\end{array}$ \\
\hline
\end{tabular}

Rev. Eletrônica Mestr. Educ. Ambient. Rio Grande, v. 36, n. 3, p. 141-159, set./dez. 2019. 


\begin{tabular}{|c|c|c|c|c|}
\hline Autor & $\begin{array}{c}\text { Habilidades } \\
\text { investigativas }\end{array}$ & $\begin{array}{l}\text { Formación desde } \\
\text { lo disciplinar }\end{array}$ & $\begin{array}{l}\text { Conocimiento } \\
\text { del contexto }\end{array}$ & Actitud vital \\
\hline & & & $\begin{array}{l}\text { grado de } \\
\text { conocimiento y } \\
\text { madurez } \\
\text { intelectual. }\end{array}$ & \\
\hline $\begin{array}{c}\text { Richard } \\
\text { Paul et al } \\
1989\end{array}$ & $\begin{array}{l}\text { Desarrollar un } \\
\text { punto de vista } \\
\text { personal: elaborar } \\
\text { o examinar } \\
\text { creencias, } \\
\text { argumentos o } \\
\text { teorías. } \\
\text { Evaluar la } \\
\text { credibilidad de } \\
\text { las fuentes de } \\
\text { información. } \\
\text { Comparar } \\
\text { situaciones } \\
\text { análogas: } \\
\text { transferir lo } \\
\text { comprendido a } \\
\text { nuevos contextos. } \\
\text { Razonar de } \\
\text { manera } \\
\text { dialogística: } \\
\text { comparar tesis, } \\
\text { interpretaciones o } \\
\text { teorías. } \\
\text { Evaluar los } \\
\text { hechos } \\
\text { comprobados y } \\
\text { los hechos } \\
\text { supuestos. }\end{array}$ & $\begin{array}{l}\text { Pensar de forma } \\
\text { autónoma. } \\
\text { Leer de manera } \\
\text { crítica: aclarar o } \\
\text { analizar textos. } \\
\text { Establecer } \\
\text { vínculos } \\
\text { interdisciplinarios. } \\
\text { Reflexionar con } \\
\text { precisión sobre el } \\
\text { pensamiento: } \\
\text { emplear un } \\
\text { vocabulario } \\
\text { adecuado. }\end{array}$ & $\begin{array}{l}\text { Analizar o } \\
\text { evaluar } \\
\text { argumentos, } \\
\text { interpretaciones, } \\
\text { opiniones o } \\
\text { teorías. } \\
\text { Escuchar de } \\
\text { manera crítica: } \\
\text { dominar el arte } \\
\text { activo de } \\
\text { escuchar. } \\
\text { Distinguir entre } \\
\text { los hechos } \\
\text { pertinentes y los } \\
\text { que no lo son. }\end{array}$ & $\begin{array}{l}\text { Pensar de forma } \\
\text { autónoma. } \\
\text { Mostrar } \\
\text { perseverancia } \\
\text { intelectual. } \\
\text { Comparar y } \\
\text { confrontar los } \\
\text { ideales con la } \\
\text { realidad. }\end{array}$ \\
\hline $\begin{array}{l}\text { Tardiff } \\
1992\end{array}$ & $\begin{array}{l}\text { Evaluar de } \\
\text { credibilidad de } \\
\text { una fuente. } \\
\text { Interpretar } \\
\text { documentación } \\
\text { especializada en } \\
\text { el tema. }\end{array}$ & $\begin{array}{l}\text { Elegir las } \\
\text { dimensiones del } \\
\text { pensamiento } \\
\text { crítico que se va a } \\
\text { enseñar. } \\
\text { Organizar un } \\
\text { ambiente propicio } \\
\text { para la formación } \\
\text { del pensamiento } \\
\text { crítico. }\end{array}$ & $\begin{array}{l}\text { Aplicar la } \\
\text { habilidad, } \\
\text { estrategia o } \\
\text { actitud que se } \\
\text { elija a la vida } \\
\text { cotidiana del } \\
\text { alumno, fuera } \\
\text { del ámbito } \\
\text { escolar. }\end{array}$ & \\
\hline
\end{tabular}

Rev. Eletrônica Mestr. Educ. Ambient. Rio Grande, v. 36, n. 3, p. 141-159, set./dez. 2019. E-ISSN 1517-1256 


\begin{tabular}{|c|c|c|c|c|}
\hline Autor & $\begin{array}{c}\text { Habilidades } \\
\text { investigativas }\end{array}$ & $\begin{array}{l}\text { Formación desde } \\
\text { lo disciplinar }\end{array}$ & $\begin{array}{l}\text { Conocimiento } \\
\text { del contexto }\end{array}$ & Actitud vital \\
\hline & & $\begin{array}{l}\text { Planificar la } \\
\text { enseñanza de las } \\
\text { dimensiones } \\
\text { elegidas del } \\
\text { pensamiento } \\
\text { crítico. } \\
\text { Evaluar la calidad } \\
\text { de la enseñanza- } \\
\text { aprendizaje de las } \\
\text { dimensiones del } \\
\text { pensamiento } \\
\text { crítico que se } \\
\text { efectúe en el } \\
\text { marco del curso. }\end{array}$ & & \\
\hline \multirow[t]{2}{*}{$\begin{array}{l}\text { Beyer } \\
1987\end{array}$} & $\begin{array}{l}\text { Examinar o } \\
\text { evaluar los } \\
\text { supuestos. } \\
\text { Evaluar los } \\
\text { hechos } \\
\text { comprobados y } \\
\text { los supuestos. } \\
\text { Dilucidar } \\
\text { problemas, } \\
\text { conclusiones o } \\
\text { creencias. }\end{array}$ & $\begin{array}{l}\text { Aplicación } \\
\text { frecuente a otras } \\
\text { áreas de estudio. } \\
\text { La pertinencia del } \\
\text { área de estudio } \\
\text { respecto a las } \\
\text { dimensiones } \\
\text { elegidas. } \\
\text { Evaluar la calidad } \\
\text { de la enseñanza- } \\
\text { aprendizaje de las } \\
\text { dimensiones del } \\
\text { pensamiento } \\
\text { crítico efectuadas } \\
\text { en el marco del } \\
\text { curso. } \\
\text { Planificar la } \\
\text { enseñanza de las } \\
\text { dimensiones } \\
\text { elegidas del } \\
\text { pensamiento } \\
\text { crítico. }\end{array}$ & $\begin{array}{l}\text { Aplicación } \\
\text { frecuente en la } \\
\text { vida del alumno. }\end{array}$ & $\begin{array}{l}\text { Manifestar } \\
\text { mente abierta. } \\
\text { Cultivar la } \\
\text { curiosidad. } \\
\text { Mantener la } \\
\text { lucidez. } \\
\text { Ejercer la } \\
\text { creatividad. } \\
\text { Manifestar } \\
\text { imparcialidad. }\end{array}$ \\
\hline & $\begin{array}{l}\text { La insistencia en } \\
\text { la búsqueda de } \\
\text { una solución a un } \\
\text { problema que no } \\
\text { es aparente de } \\
\text { inmediato. }\end{array}$ & $\begin{array}{l}\text { Verificación del } \\
\text { propio trabajo en } \\
\text { los planos de la } \\
\text { exactitud y la } \\
\text { precisión. }\end{array}$ & $\begin{array}{l}\text { La aptitud de } \\
\text { escuchar a los } \\
\text { demás, } \\
\text { demostrar } \\
\text { empatía y } \\
\text { comprender sus }\end{array}$ & $\begin{array}{l}\text { Ejercicio de un } \\
\text { mejor control } \\
\text { sobre la } \\
\text { impulsividad. } \\
\text { Flexibilidad de }\end{array}$ \\
\hline
\end{tabular}

Rev. Eletrônica Mestr. Educ. Ambient. Rio Grande, v. 36, n. 3, p. 141-159, set./dez. 2019. E-ISSN 1517-1256 


\begin{tabular}{|c|c|c|c|c|}
\hline Autor & $\begin{array}{c}\text { Habilidades } \\
\text { investigativas }\end{array}$ & $\begin{array}{l}\text { Formación desde } \\
\text { lo disciplinar }\end{array}$ & $\begin{array}{l}\text { Conocimiento } \\
\text { del contexto }\end{array}$ & Actitud vital \\
\hline $\begin{array}{c}\text { Newmann } \\
1990\end{array}$ & - & $\begin{array}{l}\text { Utilización de } \\
\text { conocimientos } \\
\text { adquiridos en clase } \\
\text { en contextos } \\
\text { nuevos. }\end{array}$ & $\begin{array}{l}\text { puntos de vista. } \\
\text { Flexibilidad de } \\
\text { la forma de } \\
\text { pensar. } \\
\text { Capacidad de } \\
\text { poner en duda } \\
\text { las ideas } \\
\text { emitidas, de } \\
\text { descubrir } \\
\text { problemas y } \\
\text { formularlos } \\
\text { adecuadamente. } \\
\text { Capacidad de } \\
\text { pensar junto con } \\
\text { los demás. }\end{array}$ & $\begin{array}{l}\text { la forma de } \\
\text { pensar. } \\
\text { Aprovechar } \\
\text { conocimientos } \\
\text { adquiridos y } \\
\text { experiencias } \\
\text { vividas. } \\
\text { Expresarse y } \\
\text { pensar con } \\
\text { precisión, } \\
\text { Aprovechar } \\
\text { todos los } \\
\text { sentidos para } \\
\text { asimilar la } \\
\text { información. } \\
\text { Manifestar } \\
\text { emoción, gusto } \\
\text { por la } \\
\text { investigación, } \\
\text { curiosidad y } \\
\text { placer en el } \\
\text { momento de } \\
\text { resolver un } \\
\text { problema. } \\
\text { La } \\
\text { metacognición, } \\
\text { o conciencia del } \\
\text { pensamiento } \\
\text { propio. }\end{array}$ \\
\hline $\begin{array}{c}\text { Glatthorn } \\
\text { y Baron } \\
1985\end{array}$ & $\begin{array}{l}\text { Recurrir a la } \\
\text { autocrítica, } \\
\text { considera las } \\
\text { diferentes } \\
\text { posibilidades que } \\
\text { se le presentan y } \\
\text { busca las } \\
\text { evidencias que } \\
\text { comprueben los } \\
\text { aspectos } \\
\text { antagónicos de } \\
\text { una situación. } \\
\end{array}$ & $\begin{array}{l}\text { Definir sus } \\
\text { objetivos de } \\
\text { manera profunda, } \\
\text { exenta de revisión } \\
\text { si es necesario. }\end{array}$ & $\begin{array}{l}\text { Actuar en } \\
\text { situaciones } \\
\text { problemáticas y } \\
\text { tolera la } \\
\text { ambiguiedad. }\end{array}$ & $\begin{array}{l}\text { Reflexionar, } \\
\text { delibera y } \\
\text { efectúa una } \\
\text { búsqueda } \\
\text { expedita, cuando } \\
\text { es necesario. } \\
\text { Otorgar valor a } \\
\text { la racionalidad y } \\
\text { tiene fe en la } \\
\text { eficacia de este } \\
\text { pensamiento. }\end{array}$ \\
\hline
\end{tabular}

Elaborado con recursos tomados de (Boisvert, 2004)

Rev. Eletrônica Mestr. Educ. Ambient. Rio Grande, v. 36, n. 3, p. 141-159, set./dez. 2019. 
De igual manera, desde las consideraciones de los autores mencionados, se reconocen orientaciones que apoyan prácticas pedagógicas para el pensamiento crítico desde la perspectiva social como acciones razonables en las que se identifican tres grandes características, estas son: vivir juntos, sentido social y sensibilidad al contexto; para las cuales se relacionan en el cuadro a continuación las principales habilidades que ha de propiciar el docente en sus prácticas:

Cuadro 2 habilidades de pensamiento crítico para la razonabilidad

\begin{tabular}{|c|c|c|c|}
\hline Autor & Vivir juntos & Sentido social & $\begin{array}{l}\text { Sensibilidad del } \\
\text { contexto }\end{array}$ \\
\hline $\begin{array}{c}\text { Lipman } \\
2016\end{array}$ & $\begin{array}{l}\text { Ser consciente de los } \\
\text { errores del pensamiento } \\
\text { propio. } \\
\text { Reconocer que es } \\
\text { erróneo dar algunas } \\
\text { cosas por supuestas. }\end{array}$ & $\begin{array}{l}\text { Llegar a acuerdos en los } \\
\text { que se concertan puntos } \\
\text { de vista divergentes. } \\
\text { Emitir juicios con } \\
\text { fundamentos razonables } \\
\text { condicionados por las } \\
\text { experiencias y normas } \\
\text { de una sociedad que } \\
\text { determinan lo que es } \\
\text { razonablemente } \\
\text { aceptable. } \\
\text { Detectar errores en la } \\
\text { forma de pensar de los } \\
\text { demás. } \\
\text { Identificar } \\
\text { inconsistencias en las } \\
\text { discusiones. } \\
\text { Generar valores } \\
\text { compartidos, tales como } \\
\text { ideales, propósitos, } \\
\text { objetivos, metas y fines. }\end{array}$ & $\begin{array}{l}\text { Entender la diferencia } \\
\text { entre matices de } \\
\text { significado que } \\
\text { provienen de diferencias } \\
\text { culturales, de diferentes } \\
\text { perspectivas personales o } \\
\text { de puntos de vista. } \\
\text { Reconocer las diferencias } \\
\text { teniendo en cuenta la } \\
\text { diversidad lingüística, la } \\
\text { diversidad disciplinar y } \\
\text { los marcos de referencia. } \\
\text { Buscar diferencias entre } \\
\text { situaciones } \\
\text { aparentemente similares } \\
\text { pero cuyas consecuencias } \\
\text { son diferentes. } \\
\text { Percibir discrepancias } \\
\text { entre situaciones } \\
\text { aparentemente similares, } \\
\text { del presente y del } \\
\text { pasado. } \\
\text { Entender las } \\
\text { convenciones, normas, } \\
\text { regularidades, } \\
\text { uniformidades, } \\
\text { precedentes y } \\
\text { tradiciones. }\end{array}$ \\
\hline $\begin{array}{l}\text { Ennis } \\
1987\end{array}$ & $\begin{array}{l}\text { Vincular el diálogo con } \\
\text { el Otro, el }\end{array}$ & $\begin{array}{l}\text { Construir posibilidades } \\
\text { conjuntas para el }\end{array}$ & $\begin{array}{l}\text { Ser sensible a los } \\
\text { sentimientos, nivel de }\end{array}$ \\
\hline
\end{tabular}

Rev. Eletrônica Mestr. Educ. Ambient. Rio Grande, v. 36, n. 3, p. 141-159, set./dez. 2019. 


\begin{tabular}{|c|c|c|c|}
\hline Autor & Vivir juntos & Sentido social & $\begin{array}{l}\text { Sensibilidad del } \\
\text { contexto }\end{array}$ \\
\hline & $\begin{array}{l}\text { reconocimiento del } \\
\text { Otro. } \\
\text { Mostrar apertura a la } \\
\text { escucha del pensamiento } \\
\text { ajeno. }\end{array}$ & $\begin{array}{l}\text { bienestar individual y } \\
\text { colectivo. } \\
\text { Ser razonable es estar } \\
\text { dispuesto a la crítica de } \\
\text { sus pares y al debate } \\
\text { con otros para discutir } \\
\text { aquellos pensamientos } \\
\text { que lo diferencian de él. }\end{array}$ & $\begin{array}{l}\text { conocimiento y grado de } \\
\text { sofisticación de los } \\
\text { Otros. } \\
\text { Proceder de manera } \\
\text { ordenada de acuerdo con } \\
\text { cada situación. } \\
\text { Observar y juzgar los } \\
\text { informes derivados de la } \\
\text { observación. }\end{array}$ \\
\hline $\begin{array}{l}\text { Rawls } \\
1993\end{array}$ & $\begin{array}{l}\text { Considerar que el ser } \\
\text { razonable no es estar } \\
\text { motivado por el bien } \\
\text { general como tal, sino } \\
\text { desear por sí mismo un } \\
\text { mundo social en el que } \\
\text { se pueda cooperar con } \\
\text { otros en términos que } \\
\text { todos pueden aceptar } \\
\text { desde el entendimiento } \\
\text { de libertad e igualdad. }\end{array}$ & $\begin{array}{l}\text { Considerar a los otros } \\
\text { individuos como libres e } \\
\text { iguales. } \\
\text { Entablar relaciones de } \\
\text { cooperación sobre bases } \\
\text { equitativas. } \\
\text { Estar dispuesto a } \\
\text { proponer principios y } \\
\text { estándares colectivos. } \\
\text { Concordar parcialmente } \\
\text { con otras concepciones } \\
\text { razonables, } \\
\text { conformando un } \\
\text { "consenso sobrepuesto". } \\
\text { Aceptar la convivencia } \\
\text { tolerante de diferentes } \\
\text { estilos de vida no } \\
\text { intolerantes y la } \\
\text { implantación de los } \\
\text { derechos e instituciones } \\
\text { aue ello imnlica. }\end{array}$ & $\begin{array}{l}\text { Evaluar y sopesar la } \\
\text { relevancia de evidencias } \\
\text { empíricas. } \\
\text { Verificar hipótesis } \\
\text { científicas, la pluralidad } \\
\text { de concepciones morales, } \\
\text { filosóficas Y religiosas. }\end{array}$ \\
\hline
\end{tabular}

Elaborado con recursos tomados de (Boisvert, 2004)

Las prácticas pedagógicas para el desarrollo del pensamiento crítico racional en los campos disciplinares; resulta relevante la reflexión de la propia práctica por parte de los docentes; varios autores coinciden en mencionar la importancia de la planificar la enseñanza de acuerdo con las dimensiones del pensamiento crítico, así mismo evaluar la calidad de la enseñanza, analizar la pertinencia de lo enseñado (Tardif, 1992) y (Beyer, 
1987). También se resaltan el diseño de actividades de aprendizaje en las que intervengan el pensamiento lógico como son la formulación y valoración de juicios (Ennis, 1987), evaluación de argumentos y supuestos, verificación de la calidad de las fuentes (Paul, 1989), entre otras.

En todos los casos, el desarrollo del pensamiento crítico racional requiere involucrar la reflexión del estudiante en la conciencia de su propio pensamiento, la toma de conciencia lo vincula con la problemática y situaciones específicas; para Ennis(1987)en estas acciones el estudiante razona sus sentimientos, conocimientos, el grado de madurez intelectual y la forma como utiliza el conocimiento para resolver problemas disciplinares en los que se logren analizar las implicaciones individuales, sociales y contextuales de tales soluciones. Con lo anterior se considera que el pensamiento crítico es una actitud vital demostrada a través de habilidades personales.Ennis(1987) y Bayer(1987) planean habilidades de pensamiento tales como disponer de una mente abierta mostrar esfuerzo constante por estar informado, mantener la atención y el ánimo, ser perseverante intelectualmente, cultivar la curiosidad. ParaNeuwmann(1990) otras habilidades son el control de la impulsividad y del pensamiento, manifestar la emoción, gusto, curiosidad por la investigación; y el placer en el momento de resolver un problema.

También el conocimiento del contexto se considera factor determinante para la apropiación de los aspectos disciplinares; en consecuencia la práctica pedagógica como espacio social de comunicación e interacción, se convierte en el escenario para que los estudiantes expongan de manera crítica sus argumentos Ennis(1987) y Paul(1989), enuncien su postura frente al problema, busquen solución de conjunto, piensen junto con los demás, analicen, argumenten y justifiquen a partir de diversas perspectivas (Ennis, 1987). Así mismo escuchen de manera crítica, con empatía y comprensión a los demás y distingan los hechos pertinentes de los que no lo son (Neuwmann, 1990) y (Paul, 1989). En suma, lapráctica pedagógica propicia escenarios sociales en los que circulan las reflexiones sobre la vida cotidiana, el contexto y las problemáticas que se abordan a partir de procesos investigativos como una manera de hacer uso críticode la teoría, para llegar la comprensión y resolución de dichos problemas.

Sin duda, las prácticas pedagógicas que más aportan para el desarrollo del pensamiento crítico desde la racionalidad disciplinar son las que se relacionan con la formación investigativa;Ennis(1987) y Tardif(1992) consideran que en ella se desarrolla habilidades como la evaluación de credibilidad, comprensión e interpretación de documentación especializada, transferencia de lo comprendido a los nuevos contextos. Por Rev. Eletrônica Mestr. Educ. Ambient. Rio Grande, v. 36, n. 3, p. 141-159, set./dez. 2019. E-ISSN 1517-1256 
otro ladoPaul(1989) menciona que se capitaliza el desarrollo de un punto de vista propio y se fortalece con el desarrollo de las habilidades investigativas. Lo cual se explica a partir de la relación que tiene la resolución de problemas y la comprensión de los fenómenos con los conocimientos disciplinares y las habilidades de pensamiento; de ahí la importancia de que los profesores traigan al aula experiencias para el aprendizaje en el que el factor común sea la problematización de los sucesos y el conocimiento del contexto.

Entre las habilidades que más relevancia presenta en la formación para la razonabilidad son las que se desarrollan para vivir juntos, entre ellas se reconocen el diálogo con otros segúnEnnis(1987), la conciencia sobre los propios pensamientos de acuerdo conLipman(1916) y el deseo de cooperar y trabajar con otros planteado porRawls(1993). De ahí la importancia de que las prácticas pedagógicas brinden alternativas para el diálogo, el reconocimiento del Otro en sus saberes y necesidades; el espacio para la escucha y el debate, para la cooperación y el entendimiento de las igualdades y libertades de los Otros. Así mismo ayudar a los estudiantes a ser conscientes de sus propios pensamientos y conocimientos para que con base en ellos logren identificar los errores presentes en sus realidades inmediatas, cuestionarlas, debatirlas y argumentar la perspectiva de su propia mirada.

El vivir juntos trae consigo las habilidades que se adquieren y demuestran en la convivencia y las cuales dotan de sentido social las acciones de los sujetos, por eso las prácticas pedagógicas han de fortalecer la búsqueda de acuerdos en los que se concierten puntos de vista divergentes, se identifiquen inconsistencias en las discusiones, se propicien espacios para la discusión, la crítica y se generen valores compartidos. Estas acciones vinculan necesariamente el respeto y la consideración de los individuos por los Otros, su reconocimiento como seres humanos libres e iguales y desde esta perspectiva fundar bases de cooperación, trabajo colectivo en el que las metas e ideales se conviertan en un asunto social.

A partir de la comprensión de que todo asunto social se da en un contexto y que las prácticas pedagógicas son actos sociales; es conveniente tratar sobre la importancia de sensibilizar a los estudiantes sobre lo que acontece en el contexto. Para Lipman(2016)esta sensibilidad se favorece con actividades en las que los estudiantes se enfrenten a problemáticas culturales, sociales presentes y pasadas en las que apliquen y apropien los conocimientos disciplinares. Por su parte Ennis(1987) la sensibilidad se trata desde el punto de vista del sentimiento y la consideración por los sentimientos del Otro y su conocimiento. Y desde la mirada deRawls(1993), ha de tratarse desde una perspectiva Rev. Eletrônica Mestr. Educ. Ambient. Rio Grande, v. 36, n. 3, p. 141-159, set./dez. 2019. E-ISSN 1517-1256 
científica, es decir el desarrollo de la sensibilidad a las problemáticas, la observación, la vivencia y la respectiva interpretación a la luz de las visiones pluralistas, morales, filosóficas Y religiosas.

Por lo anterior es relevante que la práctica pedagógica integre saberes, experiencias y reflexiones que guíen al estudiante hacia una postura crítica disciplinar y social. En este orden de ideas, se entendería que la formación en pensamientocríticovista desde la racionalidad conllevaun saber disciplinar puesto en la práctica con creatividad y reflexividad, que esté orientado a la búsqueda de alternativas sobre problemáticas socialmente relevantes. Esto teniendo en cuenta que educar no es simplemente un ejercicio que apunte a fines teóricos en las diversas áreas del conocimiento sino como un conjunto de experiencias reflexionadas, intencionadas para generar cambios individuales y colectivos que permitan a estudiantes y docentesentender la realidad y actuar en consecuencia para transformarla.

\section{CONSIDERACIONES FINALES}

Las prácticas pedagógicas para el pensamiento crítico implican propiciar las experiencias y escenarios de aprendizaje para el desarrollo del pensamiento aplicado en un contexto donde ocurren múltiples situaciones (problemáticas) de una sociedad. En consecuencia, en el pensamiento críticoconvergen las habilidades cognitivas; conocimientos disciplinares y científicos; saberes, experiencias y reflexiones sociales; actitudes, y disposiciones mentales y personales para la vida en común.

Las prácticas pedagógicas para la racionalidad involucranespacios de comunicación e interacción entre el estudiante, docente y su contexto; lo que permite así la apropiación de los conocimientos disciplinares de forma reflexiva.A partir de los fenómenos y problemas del entorno, para generar la conciencia de su propio pensamiento. Por ello la importancia de que el docente fomente la intervención del pensamiento lógico, crítico, creativo y reflexivo en sus actividades de aula y fuera de ella

La práctica pedagógica como espacio social de comunicación e interacción, se reconoce como un factor determinante la sensibilidad al contexto, ya que sirve de insumo al docente para nutrir su estrategia de aula convirtiéndola en un escenario propicio para que los estudiantes evalúen, reflexionen y expongan de manera crítica sus argumentos frente a una situación mostrada, de tal manera que estén en capacidad de enunciar su postura frente a una problemática, además de buscar una solución de conjunto que integre el pensamiento Rev. Eletrônica Mestr. Educ. Ambient. Rio Grande, v. 36, n. 3, p. 141-159, set./dez. 2019. E-ISSN 1517-1256 
colectivo, la empatía y comprensión hacia los demás, así como la distinción de los hechos pertinentes de aquellos que no lo son. Esto es la práctica pedagógica para la racionalidad, para la vida en sociedad.

\section{REFERENCIAS}

Barrera Pedemonte, F. (2009). Desarrollo del profesorado: El saber pedagógico y la tradición del profesor como profesional reflexivo (págs. 42-51). Santiago de Chile: Universidad de Chile.

Bellocchio Albornoz, M. (2005). La racionalidad pedagógica. Hacia una sociedad éticamente constituida. Recuperado el 23 de 8 de 2018, de http://200.23.113.51/pdf/21703.pdf

Beyer, B. K. (1987). En Practical Strategies for the Teaching of Thinking (pág. 273). Boston: Allyn and Bacon.

Boisvert, J. (2004). La formación del pensamiento crítico. Teoría y práctica. México D.F.: Fondo de Cultura Económica.

Carr, W., \& Kemmis, S. (1986). Teoría crítica de la enseñanza. La investigación-acción en la formación del profesorado. Barcelona: Martinez Roca.

Diaz, M. (1990). En De la práctica pedagógica al texto pedagógico. Pedagogía y saberes (págs. 14-27). México D.F: Universidad Pedagógica Nacional.

Ennis, R. H. (1985). A Logical Basis for Measuring Critical Thinking Skills. Educational Leadership, 43(2), 44-48.

Ennis, R. H. (1987). En A Taxonomy of Critical Thinking Dispositions and Abilities (págs. 9-25). Nueva York: Freeman Times Books.

Fayad, J. (2002). De la práctica docente a la práctica pedagógica. Revista Ciencias Humanas $N^{\circ} 9,131-141$.

Freire, P. (2004). Pedagogía de la autonomía. México D.F.: Siglo XXI.

Glatthorn, A. A., \& Baron, J. (1985). The Good Thinker. En C. ArthurL., Developing Minds. A Resource Book for Teaching Thinking (págs. 49-53). Virginia: Association for Supervision and Curriculum Development.

Huberman, S. (1999). Cómo se forman los capacitadores. Arte y saber de su profesión. Barcelona, España: Paidós Ibérica.

Lipman, M. (2003). Thinking in Education (Segunda ed.). Nueva York: Cambridge University Press.

Rev. Eletrônica Mestr. Educ. Ambient. Rio Grande, v. 36, n. 3, p. 141-159, set./dez. 2019. E-ISSN 1517-1256 
Lipman, M. (2016). El lugar del pensamiento en la educación. (M. Gómez Pérez, Ed., \& M. Gómez Pérez, Trad.) Barcelona, España: Octaedro.

Martín Sánchez, M. (2009). En Rol del docente, racionalidad pedagógica y formación del profesorado en entornos virtuales de aprendizaje (págs. 2-4). Cáceres, España:

Universidad de Extremadura.

Martinez Boom, A. (1990). Teoría Pedagógica. Una mirada arqueológica a la pedagogía. Pedagogía y Saberes, 7-13.

Neuwmann, F. M. (1990). Higher Order Thinking in Teaching Social Studies: a Rationale for the Assessment of Classroom Thoughtfulness. Journal of Curriculum Studies, vol 22, Num 1, 41-56.

Ortega, J. O. (2005). Poder y práctica pedagógica. Santafé de Bogotá: Magisterio. Parra Chacón, E., \& Lago de Vergara, D. (2003). Didáctica para el desarrollo del pensamiento crítico en estudiantes Universitarios. Recuperado el 25 de 9 de 2018, de http://scielo.sld.cu/scielo.php?script=sci_arttext\&pid=S0864-21412003000200009

Paul, R. W. (1989). En A. Binker, D. Martin, \& K. Adamson, Critical Thinking Handbook: High School, A Guide for Redesigning Instruction, Sonoma State University, Center for Critical Thinking and Moral Critique (págs. 265-266). California: Rohnert Park.

Rawls, J. (1971). Teoría de la justicia. (M. D. González, Trad.) Massachusetts: Harvard University Press.

Rawls, J. B. (1993). Political Liberalism. Nueva York: Cambridge University Press.

Rawls, J. B. (1993). The Domain of The Political and Overlaping Consensus. En D. Copp, J. Hampton, \& J. E. Roemer, The Idea of Democracy.Nueva York: Cambridge Unevrsity Press.

Saul, A. M. (2002). Paulo Freire y la formación de educadores. Múltiples miradas. Sao Paulo: Siglo XXI.

Tardif, J. (1992). En Pour un enseignement stratégique. L'apport de la psychologie cognitive (pág. 475). Montreal: Editions Logiques.

Universidad de Manizales. (2014). Sistema de planificación: Racionalidad y

Razonabilidad: principios que soportan la Universidad Moderna. Manizales: Centro de Publicaciones, Universidad de Manizales.

Zambrano Leal, A. Didáctica, pedagogía y saber. Santafé de Bogotá: Cooperativa editorial Magisterio, 1963

Zuluaga Garcés, O. L. Pedagogía e historia. Santafé de Bogotá: Universidad de Antioquia, 1999. 